\title{
Cognitive and Brain Reserve (CBR) Tools to Reduce the Risk of Dementia and Alzheimer
}

\author{
Mosad Zineldin \\ Department of Medicine and Optometry, Faculty of Health and Life Sciences, Linnaeus University, Växjö, Sweden \\ Email: Mosad.zineldin@lnu.se
}

How to cite this paper: Zineldin, $M$. (2018) Cognitive and Brain Reserve (CBR) Tools to Reduce the Risk of Dementia and Alzheimer. Advances in Alzheimer's Disease, 7, 93-102.

https://doi.org/10.4236/aad.2018.74007

Received: September 19, 2018

Accepted: November 12, 2018

Published: November 15, 2018

Copyright $\odot 2018$ by author and Scientific Research Publishing Inc. This work is licensed under the Creative Commons Attribution International License (CC BY 4.0).

http://creativecommons.org/licenses/by/4.0/

(c) (i) Open Access

\begin{abstract}
The study was performed to examine and assess the impact of the education, occupation and leisure time on building brain and cognitive reserves (CBR). A cross sectional study of 132 persons at age between 40 to 70 years old has been conducted. A structured questionnaire covering multiple constructs was used to collect the data. Multivariate regression results show that the three independent variables (LE, OC and ED) were statistically significant in the models with CBR as dependent variable. Leisure time and activities (LE) make the strongest unique contribution (0.683) followed by occupation (0.261) and the weak contribution of the education (0.198) to explain the dependent variable cognitive and brain reserve (CBR). The Brain and Cognitive Reserve hypothesesassumes that a rich intellectual measures and abilities a person have during her/his life enable this person to cope with difficult cognitive tasks and social events in life.
\end{abstract}

\section{Keywords}

Cognitive Reserve, Brain Reserve, Dementia, Alzheimer, Quality, Quality of Life, Neurological Brain

\section{Background}

Patient safety and good quality of care are considered to be the right of all patients [1]. According to World Alzheimer Report (2015), it is estimated that in 2015 over 10 million people in Europe and over 36 million people worldwide had dementia. The number of people with dementia is forecast to be 66 million in 2030 and 115 million by 2050 [2].

The percentage of US people with Alzheimer's dementia increases intensely with age: $3 \%$ of people age $65-74,17 \%$ of people age $75-84$ and 32\% of people age 85 or older have Alzheimer's dementia [3]. It should be noted that older age 
alone is not sufficient to cause Alzheimer's dementia but older women are most affected by Alzheimer's in the US. According to the estimates of Alzheimer Europe, the number of people with dementia in Belgium in 2012 was 191,281, representing $1.8 \%$ of the entire population. According to the Swedish Alzheimer Association (2014), approx. 1.5\% of all Swedish people have some type of dementia [4]. The number is higher in Finland and 54 people die per 100,000 in the Finnish population every year due to Alzheimer's and different type of dementias. Although, there is not much official sources of Alzheimer's statistics in the Middle East, the WHO dementia report states that the Middle East and North Africa will see a $125 \% \mathrm{t}$ increase of elderly people in cases by 2050 and estimates that almost $6 \%$ of those over 60 years old suffer from it [5].

Thus, new medical, social and economic strategies to prevent or delay AD and dementia symptoms are critically needed. Pharmacologic and lifestyle interventions can delay the disease [6] [7]. However, a considerable number of old and recent studies have found a correlation between brain reserve (i.e. neurological brain and behavioral or cognitive brain) level of and prevalence of dementia [8] [9] [10].

The term "reserve" was introduced in the late 1980s to describe the ability of different individuals to cope with physiological and or pathological cognitive decline. Brain reserve is the prevalent construct of the potential ability of the brain to cope with neuronal damage [11]. Reserve can also be defined as the brain's resilience: that is, the possibility of the brain itself coping with increasing the brain damage; the brain reserve hypothesis is primarily a passive-quantitative model related to individual differences (e.g., brain size and synapse count). The authors mean that a greater brain reserve is considered as a protective factor, and a lower one indicates vulnerability [12].

It should be noted that dementia causes many changes in people's lives. Dementia can take different forms depending on the damaged part of the brain. Some of the symptoms are impaired memory and lack of the ability to plan and carry out everyday tasks. Problems in language, time perception and orientation are other impaired cognitive abilities. Anxiety and behavioral changes can belong to the dementia. Other problems are attention, recognition, executive activities, and speech problems. Depression, apathy and aggression are also comorbid symptoms [13].

The treatment of cognitive decline and dementia should be seen from a holistic perspective as it includes medical, neurological, cognitive and behavioral as well as technical, technological and social tools and strategies. The cognitive or behavioral brain reserve hypothesis argues that the brain actively attempts to cope with damage by using pre-existing cognitive processes or enlisting compensatory strategies [11] [12] [14].

Cognitive brain reserve (CBR) means that a complex mental activity across the lifespan allows flexible cognitive repertoires to be deployed in the face of underlying neural dysfunction. Accordingly, people with a high CBR can with- 
stand more age-related changes and disease-related pathologies by effectively and flexibly using cognitive paradigms or compensatory brain networks [15]. Behavioral or cognitive reserve according to epidemiological studies can be estimated from autobiographical and demographic data such as age, sex, education levels, occupational complexity and frequency of mentally stimulating lifestyle pursuits [9] [10].

Education, occupation, leisure time and other higher lifelong mental stimulation can be indicators of intelligence may exert a direct protective effect by enhancing the brain's reserve capacity, e.g. by increasing neocortical synapse density. Adverse conditions for neurocognitive development in early life may lower cognitive ability, reduce the likelihood of higher educational attainment, and increase the susceptibility to neurodegenerative disease in old age [16] [17] [18].

Leisure activities, lifelong learning and other cognitive activities can be efficient tools and working mechanism for informal carers to increase the cognitive reserve of elderly persons as effective interventions for dementia. Previous studies show that there are associations between dementia and reduced participation in leisure activities in midlife, as well as between cognitive status and participation in leisure activities in old age. People with higher educational levels are more resistant to the effects of dementia as a result of having greater cognitive reserve and increased complexity of neuronal synapses [11] [19].

Like education, participation in exercises, leisure and physical activities may lower the risk of dementia by improving cognitive reserve. Physical activities and exercises can help preserve cognitive function and decrease dementia risk and Alzheimer's disease and vascular dementia because the physical activities and exercises can increase in brain-derived neurotrophic factor which is a molecule that increases neuronal survival, enhances learning, and protects against cognitive decline [20] [21].

Although Alzheimer's has a strong genetic component, lifestyle and environmental factors play a strong role in shaping its expression and timing of onset. Still, more research and studies are needed to identify the optimal way to intervene to increase brain and cognitive reserves and prevent Alzheimer's disease [9]. This study attempts to examine and assess the impact of the education, occupation and leisure time (OEL) on building brain and cognitive reserves (CBR). A preventive strategy using OEL tools might entail augmenting brain and cognitive reserve to enable favorable clinical and behavioral outcomes for any given level of pathology.

\section{Hypothesis}

The research model is illustrated in Figure 1. Based on the literature review and foregoing discussion, the following hypotheses, stated in formal fashion, are proposed:

$\mathrm{H} 1$ : there is a positive relationship between $\mathrm{CBR}$ and education;

$\mathrm{H} 2$ : there is a positive relationship between $\mathrm{CBR}$ and occupation/intellectuality 


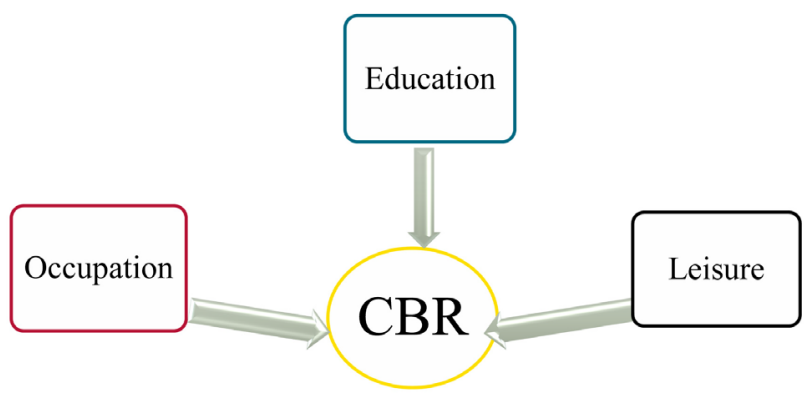

Figure 1. Research model: Structural framework of the theoretical relation.

level;

H3: there is a positive relationship between CBR and leisure activities.

\section{Method}

\subsection{Participants and Data Collection}

A random sample of 243 persons were contacting personally using different modes such as telephone, mail and face to face in random places and times during March-April 2017 and ask them to complete the survey. When it was possible, some respondents have completed the survey in restaurants, sport clubs, theatres and universities, etc. Out of the 243 distributed questioners, 132 were returned and usable, resulting in a response rate of 54.32 percent.

The criteria for selecting participants were: age between 40 and 59 years (30\%) and between 60 and over 70 years (70\%); physically independent person, i.e., able to walk between 1 - $3 \mathrm{~km}$ without assistance; and lack of cognitive impairment; disorders interfering with psychometric assessment. The participation was voluntary. All participants were fully informed about the confidentiality, content and aim of the study.

Some scales of the current study were adapted from the Alzheimer's Disease-related Quality of Life scale (QoL-AD). QoL-AD is a 13-item validated scale (National chronic care consortium and the Alzheimer's association, 2003) [22]. QoL-AD is a disease specific in some areas and health related in other areas [23]. Some other scales were adapted from Dementia Population Risk Tool (DemPoRT) developed [24]. Some scales used in the current study are:

Self-rated health such as:

- I have no chronic diseases;

- I have good explicit memory (stores facts "special events");

- I have good short-term memory (work memory): numbers, words, visualizations.

New item scales were also developed such as:

- I'm quite happy with the most of my life experiences;

- I'm good at training my brain (Physical Activity, Mind Stimulants, etc.).

Respondents answered the questionnaire by agreeing or disagreeing with the statement using a Likert scale from $1=$ strongly disagree to $5=$ strongly agree. 
The data were analyzed using regression analysis via the Statistical Package for Social Sciences (SPSS) program version 21.0. To analyses the descriptive data of the respondents and the investigated variables, this research utilized a number of steps: descriptive analysis, assessment of reliability and validity, correction analysis and regression analysis.

\subsection{Statistical Data Analysis}

The demographic details of this study show that 72 women (54.5\%) and 60 men (45.5\%) were included in this study. Their age ranged from 40 to $>70$ years old. $30.3 \%$ were between 40 - 59 and $43.9 \%$ was $60-69$ and $25.8 \%$ was $>70$ years old.

The level of education for respondents included $12 \%$ lower than high school, $28 \%$ had high school education, $41 \%$ had formal higher education, $13 \%$ had master and $6 \%$ had doctoral degrees. Seven percent had chief/head/ or senior manager positions, $25 \%$ middle manager, $47 \%$ average positions, $12 \%$ were unemployed and $8 \%$ have own businesses or self-employees.

$92 \%$ of the participants were healthy, $7 \%$ with some neurological, genetic or psychiatric illness and $1 \%$ had other illness. The participants did not receive any compensation for taking part in the study. The names and identities of the participants were anonymous. All data were collected from March to April 2015.

\subsection{CBR Scale Construction}

The CBR includes some demographic data such as gender, age, and marital status and 25 items grouped into three sections, education, life style including own health education and promotion and, and leisure time, each of which returns a sub score.

CBR-education: Years of formal education plus possible lifelong learning or training courses; reading scientific and nonscientific works, Multilanguage skills (at least 3 languages).

CBR-occupation or working life: Five different levels of working activities are intellectual involvement and personal responsibility (professors, top managers, etc.), middle managers, manual or technical work and own and professional occupation (e.g., consult, lawyer, psychologist, physician, engineer).

CBR-pleasure and leisure time: Cognitively stimulating activities carried out during pleasure and leisure time (after work). Ten items were related to this construct (e.g., actively participated in cultural activities, stimulator movies, Theaters, museums, travel, arts, play music, listen to music, actively joining social and social media activities and physical activities such as sports and dancing.

\section{Reliability and Validity}

The research instrument was tested for internal consistency with a particular scale and reliability using Cronbach's coefficient alpha estimate. As shown in Table 1, the values for all items ranges from 0.70 to 0.74 , exceeding the minimum alpha of 0.60 which is considered to be acceptable [25]. 
Table 1. Reliability data for scales.

\begin{tabular}{cc}
\hline & Cronbach's Alpha if Item Deleted \\
\hline Gender & 0.71 \\
Age (A) & 0.72 \\
Education & 0.71 \\
Pleasure and Leisure & 0.70 \\
Working/Intellectual & 0.72 \\
CBR & 0.74 \\
\hline
\end{tabular}

Pearson correlations were calculated to identify the correlations between each of the dependent variable CBR and independent variables. Table 2 shows that the majority of the bivariate correlations are positive and statistically significant.

The raw scores of the three independent variables were correlated with CBR (correlation $r=0.271$ for education; $r=0.363$ for occupation/working activity and $\mathrm{r}=0.716$ for leisure time activity).

\section{Hypotheses Testing, Results and Discussion}

\section{Hypotheses Testing and Results}

A separate regression model was conducted to assess the research hypotheses. The model as illustrated in Table 3 shows that the dependent variable CBR shows association with leisure activities, the education level as well as the occupation which is related to the intellectual and skills levels as well as how people spend their leisure time. The model only involves statistically significant variables.

Leisure time and activities (LE) makes the strongest unique contribution (0.683) followed by occupation (0.261) and the weak contribution of the education (0.198) to explaining the dependent variable cognitive and brain reserve (CBR). Hypotheses I-III were verified and accepted. Result infers that $\mathrm{R}^{2}=65 \%$ of the variation in LE explained participants CBR. The result is also consistent with the clinical investigation conducted by Foubert et al. 2012) to identify the influence of education (ED), occupation (OC), and leisure activities (LE) on the brain reserve capacity. The voxel-based morphometry (VBM) technique was used in 331 nondemented people. The study shows that there is a positive and significant association between these factors (i.e. $\mathrm{ED}, \mathrm{OC}$ and $\mathrm{LE}$ ) and the cerebral volume which is the marker of brain reserve and hence the cognitive performance on Isaac's test. Only education, according to the authors, was significantly associated with a cerebral volume including gray and white matter. The difference in gray matter volume was located in the temporoparietal lobes and in the orbitofrontal lobes bilaterally. Both this study and Foutbert et al., (2012) study reveals that education, occupation, and leisure activities were found to significantly but differently contribute to brain reserve capacity. Leisure activities and education could play a role in the constitution of cerebral reserve capacity. The result is also consistent with the empirical research findings by Nuccil et al. 
Table 2. Correlation between scale variables.

\begin{tabular}{ccccccc}
\hline & & 1 & $\mathbf{2}$ & $\mathbf{3}$ & $\mathbf{4}$ & $\mathbf{5}$ \\
\hline CBR & Pearson Correlation & 1 & & & & \\
AGE & Pearson Correlation & $0.178^{*}$ & 1 & & & \\
ED & Pearson Correlation & $0.271^{* *}$ & $0.240^{* *}$ & 1 & & \\
OC & Pearson Correlation & $0.363^{* *}$ & 0.123 & 0.147 & 1 & \\
LE & Pearson Correlation & $0.716^{* *}$ & 0.059 & 0.029 & 0.97 & 1 \\
\hline
\end{tabular}

${ }^{\star}$ Correlation is significant at the 0.05 level (2-tailed). ${ }^{*}$ Correlation is significant at the 0.01 level (2-tailed).

Table 3. Regression model for CBR.

\begin{tabular}{cccc}
\hline Variables & $\boldsymbol{\beta}$ & R2 & $\boldsymbol{P}$ \\
\hline & & 0.647 & \\
ED & 0.198 & & 0.000 \\
OC & 0.261 & 0.000 \\
LE & 0.683 & 0.000 \\
\hline
\end{tabular}

(2011) and Bickel and Curz (2009).

\section{Conclusions}

This study demonstrates strong associations of Leisure activities, Occupation and Education (LOE) and CRB and hence dementia diagnosis. While dementia is, yet, difficult or sometimes impossible to be cured, there are promising LOE strategies that may alleviate symptoms and enhance compensatory mechanisms (CBR) for those with memory or other cognitive impairments. There are also tools to increase safety and improve quality of life, daily functions, and engagement in lifestyles activities throughout the stages of the dementia and Alzheimer's disease.

Cognitively engaging leisure, mental, and physical activities, intellectually stimulating employment, and higher education and lifelong learning, are lifestyle traits that may augment brain and cognitive reserve (CBR), that may further allow those with dementia and $\mathrm{AD}$ increased ability to compensate for disease and further contribute to a better quality of life.

The CBR components studied included three main sources: education, ccupation or working activity, and pleasure and leisure time activities. This study as well as other research studies have found a clear and consistent correlation between social capital, LOE and brain and cognitive reserve (Gregory and Rentz; 2013; Foutbert et al., 2012) [26] [27] [28]. Higher education, intellectually challenging employment and leisure activities are associated with a reduced prevalence of dementia. The data indicated that all three constructs of the CBR gathered distinct and non-redundant information on lifestyles of the participants. The correlation and significances between the CBR and the three constructs illustrated in Table 4 are shown in the following. 
Table 4. Correlation and significance between study variables.

\begin{tabular}{cccc}
\hline Variables & $\boldsymbol{\beta}$ & $\mathbf{r}$ & $\boldsymbol{P}$ \\
\hline LE & 0.683 & 0.716 & 0.000 \\
OC & 0.261 & 0.363 & 0.000 \\
ED & 0.198 & 0.271 & 0.000 \\
\hline
\end{tabular}

The Brain and Cognitive Reserve hypotheses assume that a rich intellectual measures and abilities a person have during her/his life enable this person to cope with difficult cognitive tasks and social events in life. Also, many clinical trials have found that cognitive exercise may enhance cognitive reserve providing a potentially effective intervention that may help to prevent longitudinal cognitive and functional decline.

\section{Ethics and Patient Consent}

The participation was voluntary, and each of the participants could withdraw from the study at any time. All participants were fully informed about the confidentiality, content and aim of the study.

\section{Conflicts of Interest}

The author declares no conflicts of interest regarding the publication of this paper.

\section{References}

[1] Zineldin, M., Vashicheva, V. and Zineldin, J. (2014) Total Medical and Healthcare Quality, Satisfaction and Patient Safety. International Journal of Medical Sciences and Health Care, 2, 2-10.

[2] (2015) The Global Impact of Dementia. An Analysis of Prevalence, Incidence, Cost and Trends. World Alzheimer Report. https://www.alz.co.uk/research/WorldAlzheimerReport2015.pdf

[3] Hebert, L.E., Weuve, J., Scherr, P.A. and Evans, D.A. (2013) Alzheimer Disease in the United States (2010-2050) Estimated Using the 2010 Census. Neurology, 80, 1778-1783. https://doi.org/10.1212/WNL.0b013e31828726f5

[4] Swedish Dementia Centre Demenscentrum. http://www.demenscentrum.se/Fakta-om-demens/Vad-ar-demens

[5] Abyad, A. (2015) Alzheimer's in the Middle East. JSM Alzheimer's Disease and Related Dementia, 2, 1012.

[6] Post, S.G. (1999) Future Scenarios for the Prevention and Delay of Alzheimer Disease Onset in High-Risk Groups: An Ethical Perspective. American Journal of Preventive Medicine, 16, 105-110. https://doi.org/10.1016/S0749-3797(98)00139-1

[7] Schmand, B., Smit, J.H., Geerlings, M.I. and Lindeboom, J. (1977) The Effects of Intelligence and Education on the Development of Dementia. A Test of the Brain Reserve Hypothesis. Psychological Medicine, 27, 1337-1344. https://doi.org/10.1017/S0033291797005461

[8] Tucker, A.M. and Stern, Y. (2011) Cognitive Reserve in Aging. Current Alzheimer Research, 8, 354-360. 
[9] Valenzuela, M.J. and Sachdev, P. (2006) Brain Reserve and Dementia: A Systematic Review. Psychological Medicine, 36, 441-454. https://doi.org/10.1017/S0033291705006264

[10] Nucci, M., Mapelli, D. and Modinil, S. (2011) Cognitive Reserve Index Questionnaire (CRIQ): A New Instrument for Measuring Cognitive Reserve. Aging Clinical and Experimental Research, 24, 218-226.

[11] Katzman, R., Terry, R., Deteresa, R., et al. (1988) Clinical, Pathological, and Neurochemical Changes in Dementia: A Subgroup with Preserved Mental Status and Numerous Neocortical Plaques. Annals of Neurology, 23, 138-144. https://doi.org/10.1002/ana.410230206

[12] Gulmann, N. (2003) Geronto-Psykiatri. Studentlitteratur, Lund.

[13] Stern, Y. (2009) Cognitive Reserve. Neuropsychologia, 47, 2015-2028. https://doi.org/10.1016/j.neuropsychologia.2009.03.004

[14] Keller, J.N. (2006) Age-Related Neuropathology, Cognitive Decline, and Alzheimer's Disease. Ageing Research Reviews, 5, 1-13. https://doi.org/10.1016/j.arr.2005.06.002

[15] Kramer, A.F., Bherer, L., Colcombe, S.J., Dong, W. and Greenough, W.T. (2002) Cognitive Decline Is Related to Education and Occupation in a Spanish Elderly Cohort. Aging Clinical and Experimental Research, 14, 132-142. https://doi.org/10.1007/BF03324426

[16] Abbott, R.D., White, L.R., Ross, G.W., Petrovitch, H., Masaki, K.H., Snowdon, D.A. and Curb, J.D. (1988) Height as a Marker of Childhood Development and Late-Life Cognitive Function: The Honolulu-Asia Aging Study. Pediatrics, 102, 602-609. https://doi.org/10.1542/peds.102.3.602

[17] Bickel, H. and Kurz, A. (2009) Education, Occupation, and Dementia: The Bavarian School Sisters Study. Dementia and Geriatric Cognitive Disorders, 27, 548-556. https://doi.org/10.1159/000227781

[18] Salthouse, T.A. (2006) Mental Exercise and Mental Aging: Evaluating the Validity of the "Use It or Lose It" Hypothesis. Perspectives on Psychological Science, 1, 68-87. https://doi.org/10.1111/j.1745-6916.2006.00005.x

[19] Verghese, J., Lipton, R., Katz, M., Hall, C., et al. (2003) Leisure Activities and the Risk of Dementia in the Elderly. The New England Journal of Medicine, 348, 2508-2516. https://doi.org/10.1056/NEJMoa022252

[20] Podewils, L.J., Guallar, E., Kuller, L.H., et al. (2006) Physical Activity, APOE Genotype, and Dementia Risk: Findings from the Cardiovascular Health Cognition Study. American Journal of Epidemiology, 161, 639-651.

[21] Cotman, C.W. and Engesser-Cesar, C. (2002) Exercise Enhances and Protects Brain Function. Exercise and Sport Sciences Reviews, 30, 75-79. https://doi.org/10.1097/00003677-200204000-00006

[22] National Chronic Care Consortium and the Alzheimer's Association (2003) Scales and Tools for Early Identification of Dementia.

[23] Missotten, P., Dupuis, G. and Adam, S. (2016) Dementia-Specific Quality of Life Instruments: A Conceptual Analysis. International Psychogeriatric, 28, 1245-1262. https://doi.org/10.1017/S1041610216000417

[24] Ettema, T.P., Droes, R.-M., de Lange, J., Mellenbergh, J. and Ribbe, M.W. (2005) A Review of Quality of Life Instruments Used in Dementia. Quality of Life Research, 14, 675-686. https://doi.org/10.1007/s11136-004-1258-0

[25] Hair, J.F., Black, B., Babin, B., Anderson, R.E. and Tatham, R.L. (2010) Multivariate 
DataAnalysis: A Global Perspective. Pearson Education Inc., London.

[26] Jicha, G.A. and Rentz, D.M. (2013) Cognitive and Brain Reserve and the Diagnosis and Treatment of Preclinical Alzheimer Disease. Neurology, 80, 1180-1181. https://doi.org/10.1212/WNL.0b013e318289714a

[27] Foubert-Samier, A., Catheline, G., Amieva, H., Dilharreguy, B., Helmer, C., Allard, M. and Dartigues, J.F. (2012) Education, Occupation, Leisure Activities, and Brain Reserve: A Population-Based Study. Neurobiology of Aging, 33, 15-25. https://doi.org/10.1016/j.neurobiolaging.2010.09.023

[28] Takechi, S., Yoshimura, K., Oguma, Y., Saito, Y. and Mimura, M. (2017) Relationship between Social Capital and Cognitive Functions among Community-Based Elderly. Advances in Alzheimer's Disease, 6, 45-51.

https://doi.org/10.4236/aad.2017.62004 